\title{
PhosphoShield: Improving Trypsin Digestion of Phosphoproteins by Shielding the Negatively Charged Phosphate Moiety
}

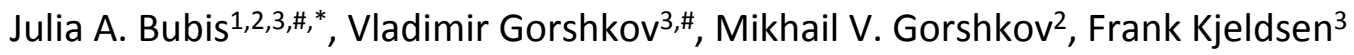 \\ 1 Moscow Institute of Physics and Technology (State University), 141700 Dolgoprudny, \\ Russia
}

2 V. L. Talrose Institute for Energy Problems of Chemical Physics, N. N. Semenov Federal Research Center for Chemical Physics, Russian Academy of Sciences, 119334 Moscow, Russia

3 Department of Biochemistry and Molecular Biology, University of Southern Denmark, DK5230 Odense M, Denmark

\# contributed equally

* corresponding author

\section{Table of content}

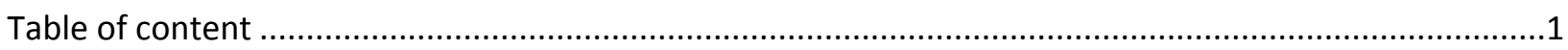

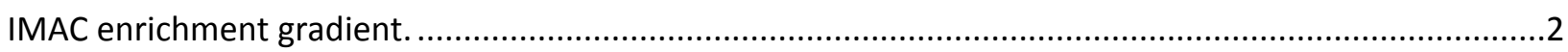

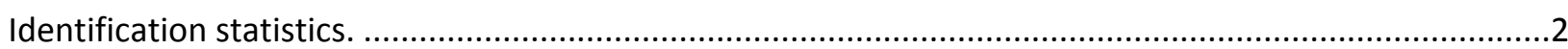

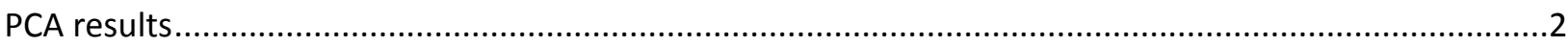

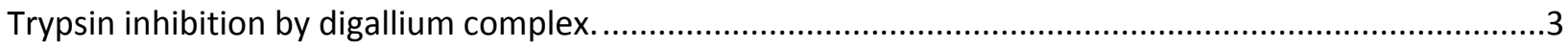

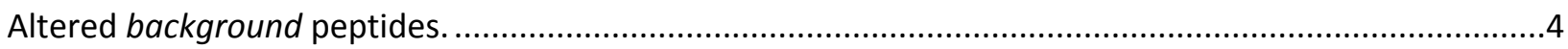




\section{IMAC enrichment gradient.}

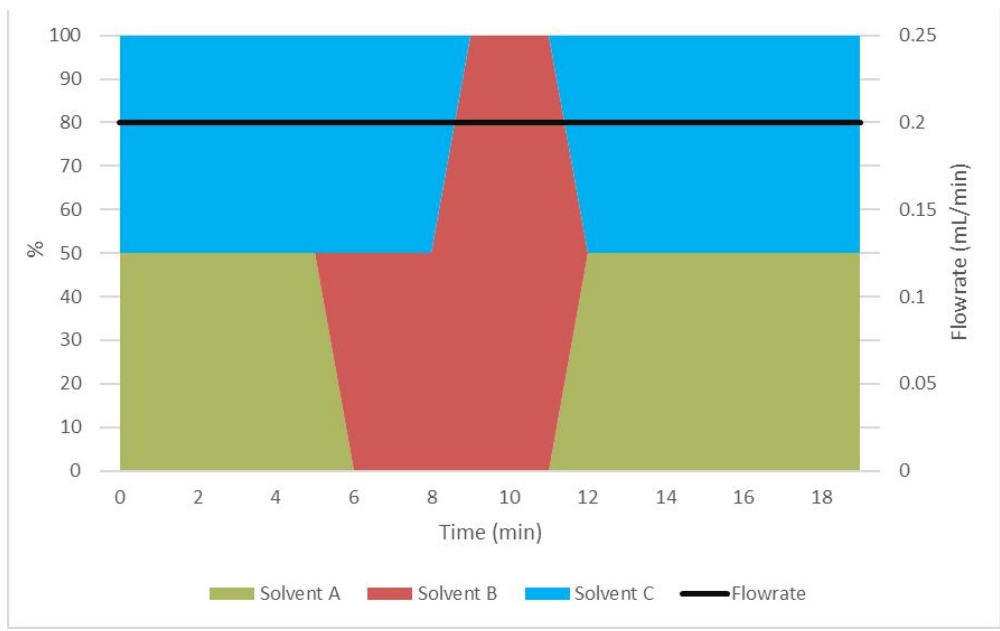

Figure S1. Gradient for IMAC enrichment. Solvent A: 0.1\% TFA in water; Solvent B: $10 \mathrm{mM}$ $\mathrm{NH}_{4} \mathrm{OH}$ (pH 10); Solvent C: 0.1\% TFA in acetonitrile.

\section{Identification statistics.}

Table S1. Identifications at PSM and peptide level for the PhosphoShield dataset.

\begin{tabular}{|l|l|l|l|l|l|}
\hline $\begin{array}{l}\text { PhosphoShield } \\
\text { Dataset }\end{array}$ & PSMs & Peptides & $\begin{array}{l}\text { Quantified } \\
\text { PSMs }\end{array}$ & $\begin{array}{l}\text { Quantified } \\
\text { and localized } \\
\text { PSMs }\end{array}$ & $\begin{array}{l}\text { Quantified } \\
\text { and localized } \\
\text { peptides }\end{array}$ \\
\hline Phosphoproteome & 19314 & 7373 & 19125 & 16853 & 6433 \\
\hline $\begin{array}{l}\text { Non-modified } \\
\text { proteome }\end{array}$ & 30708 & 14514 & 30536 & & \\
\hline
\end{tabular}


PCA results
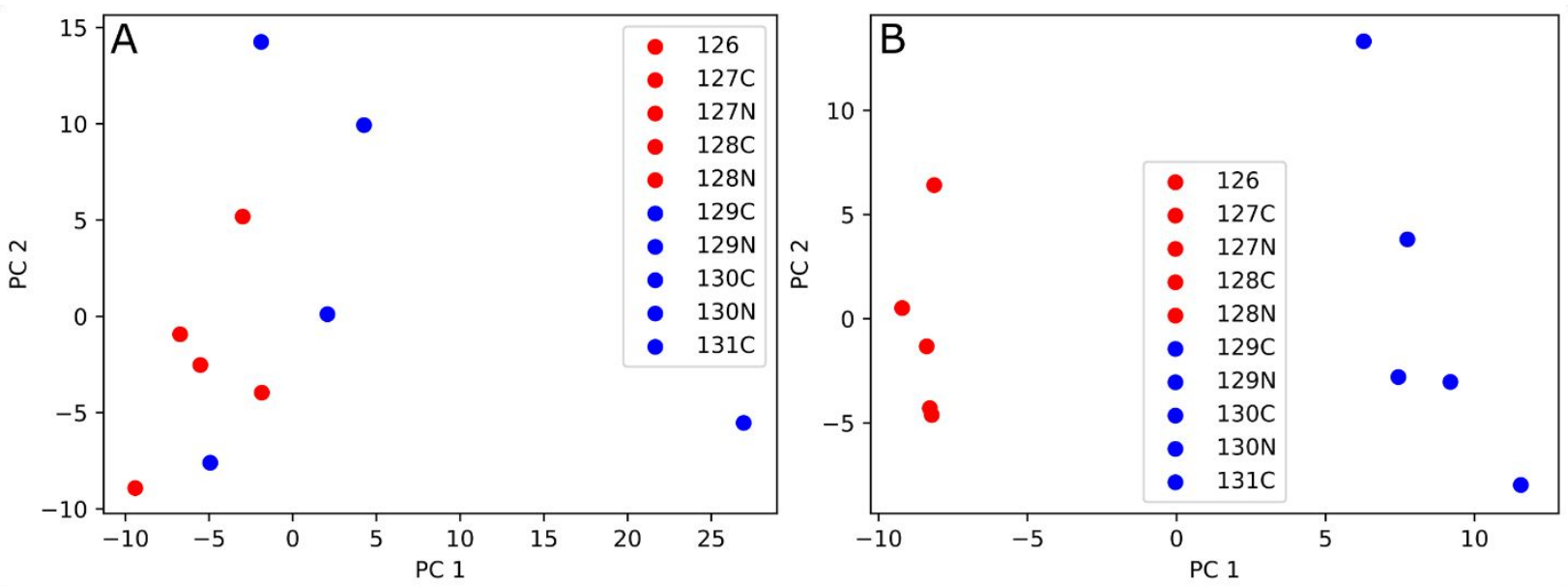

Figure S2. PCA of A - background (non-phosphorylated) peptides, and B-phosphorylated peptides. Red color denotes treated samples, blue - non-treated. 


\section{Trypsin inhibition by digallium complex.}

To investigate trypsin activity in the presence of digallium complex an enzymatic assay of trypsin inhibitor (Sigma-Aldrich) was used (Figure S3). This procedure is for determining trypsin activity using Na-BenzoylL-arginine ethyl ester (BAEE) as the substrate. The procedure is a continuous spectrophotometric rate determination ( $\mathrm{A} 253$, Lightpath $=1 \mathrm{~cm}$ ) based on the following reaction:

$$
\mathrm{BAEE}+\mathrm{H}_{2} \mathrm{O} \stackrel{\text { Trypsin }}{\longrightarrow} \mathrm{N} \alpha-\mathrm{Benzoyl}-\mathrm{L}-\text { arginine }+ \text { ethanol }
$$

BAEE is hydrolyzed by trypsin to UV-absorbing product. Trypsin activity can be measured as a slope of the UV absorbance change at A $253 \mathrm{~nm}$.

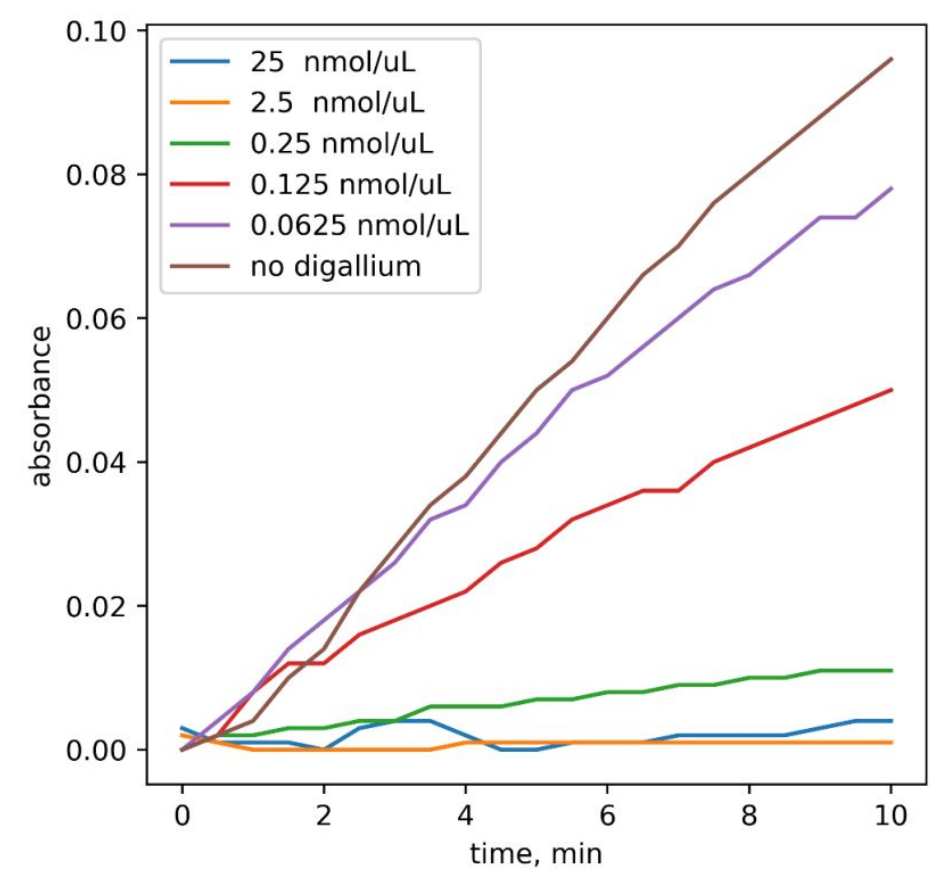

Figure S3. Trypsin activity is measured in the presence of different concentrations of digallium complex. Digallium complex in concentration $0.0625 \mathrm{nmol} / \mu \mathrm{L}$ does not affect trypsin activity, while concentrations above $0.25 \mathrm{nmol} / \mu \mathrm{L}$ lead to almost complete inhibition. 


\section{Altered background peptides.}

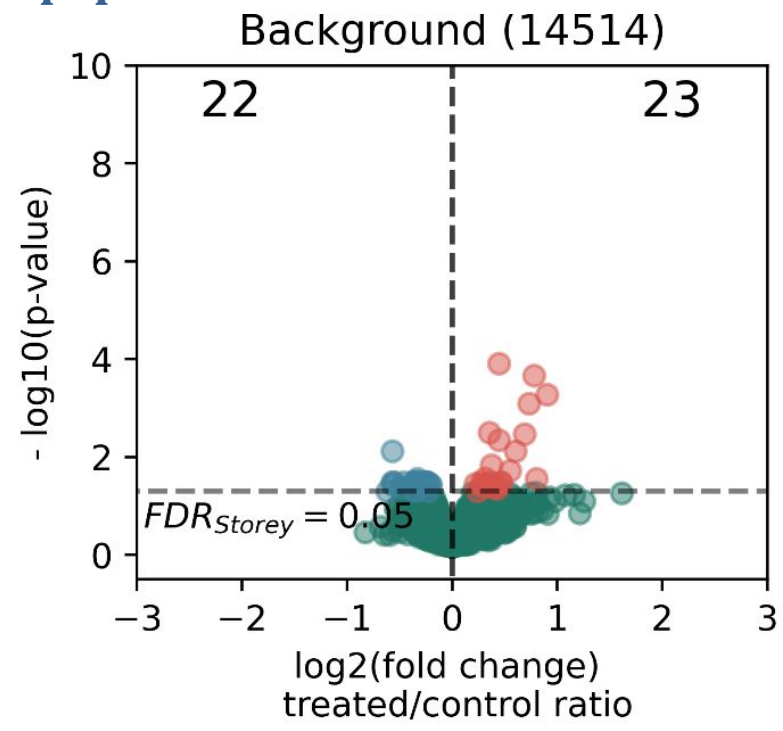

Figure S4. Volcano plot for peptides in the background group. The total number of peptides is 14514. Numbers on the right and left corner correspond to numbers of up-and downregulated peptides, respectively, passing a 5\% FDR threshold. 